\title{
Objects information as a source of image features
}

\author{
Dr. Mohamad Tariq Barakat ${ }^{1}$, Prof. Ziad A. Alqadi ${ }^{2}$ \\ Albalqa Applied University, Faculty of Engineering Technology, Jordan - Amman ${ }^{1,2}$
}

\begin{abstract}
Digital color images are the most important data types used in various vital applications, some of these applications required image features. Digital images contain variable number of objects with variable sizes. Each object contains valuable information which can be used to construct image features. In this paper research we will analyze a variety of information which are used to describe any object in the image, a methodology of objects extraction and the associated with each object will be proposed, a way of forming the image features will be discussed.
\end{abstract}

Key words: Digital image, object, features, centroid, area, extrema, orientation, convex Hull, Euclidian distance.

\section{I.INTRODUCTION}

Color digital images [1], [2] are one of the most common types of data in circulation [24], [25], [26]. This wide spread is due to the large number of vital applications that use digital images as image recognition systems, for example [6]. Digital images are characterized by their high resolution, which leads to an increase in their size to reach millions of values [15], which makes processing this huge amount of data not easy because it requires high processing time[11], [12].

To increase the efficiency of many systems that use digital images, a small set of values called image features can be used, which has the advantage of being unique to the image and can be used as a distinction to recognize the image [13], [14].

Digital images consist of a group of objects that can be easily discovered and retrieved. Each of these objects possesses a large amount of information that can be used or part of it can be used to form the features of the image. The process of detecting objects in the digital image is an easy process, as the edges of the image can be easily identified and thus objects can be identified and retrieved [4]. Getting the objects we can use the associated information to form the image features [5].

Many method are used to create digital image features victor, local binary pattern (LBP) method[8], [9], [18] and its modifications, statistical [3], K_mean clustering[20], [19], [21], linear prediction code (LPC)[7] and wavelet packet tree (WPT) decomposition[10], [22], [23] are the famous methods which are used to calculate any image features. But in our research paper we will introduce different methodology to create the features based on the extracted objects information [16], [17].

\section{II.OBJECT INFORMATION}

An object in the image is a set of 4 or 8 _connected points. Here we will describe the information associated with each object; this information contains the following data items:

* Object centroid: the center of mass of the region. The first element (as shown in figure 1) of Centroid is the horizontal coordinate (or x-coordinate) of the center of mass, and the second element is the vertical coordinate (or ycoordinate).

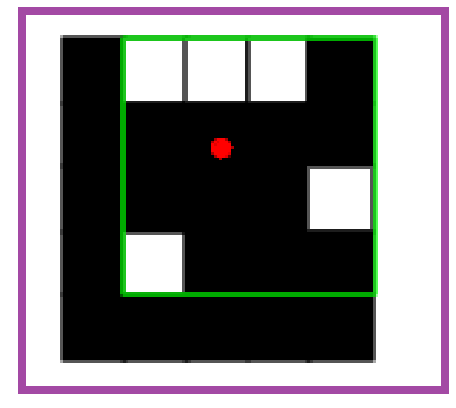

Figure 1: Object centroid

* Object area: the actual number of pixels in the region. 
\# Object extrema: the extrema points in the region. Each row of the matrix contains the $\mathrm{x}$ - and y-coordinates of one of the points. The format of the vector is [top-left top-right right-top right-bottom bottom-right bottom-left leftbottom left-top] as shown in figure 2 .

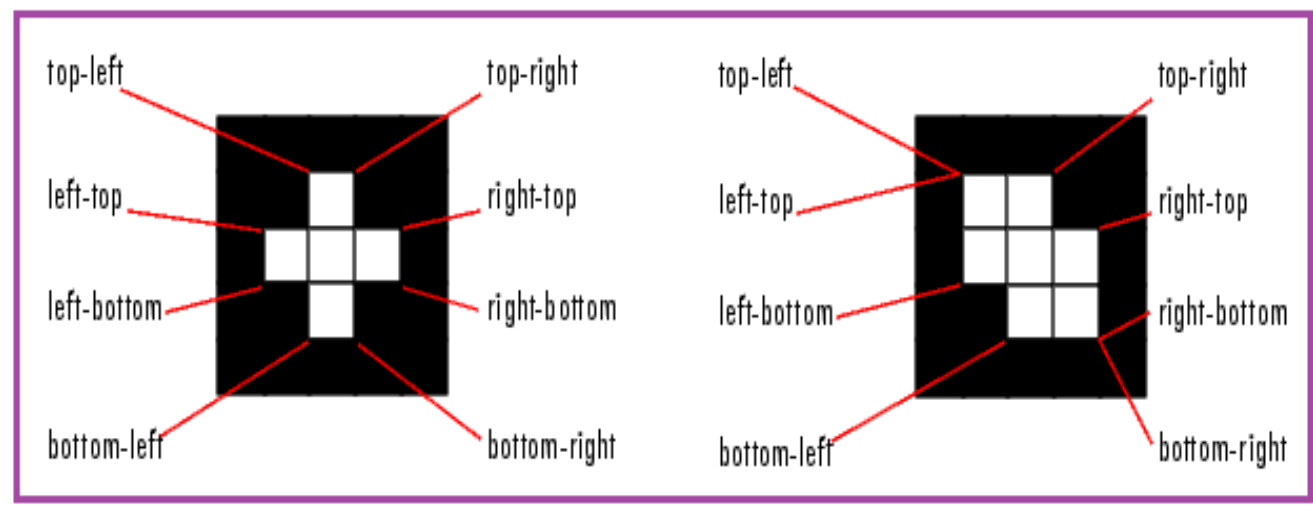

Figure 2: Object extrema

* Object orientation: the angle (in degrees) between the $\mathrm{x}$-axis and the major axis of the ellipse that has the same second-moments as the region as shown in figure 3.

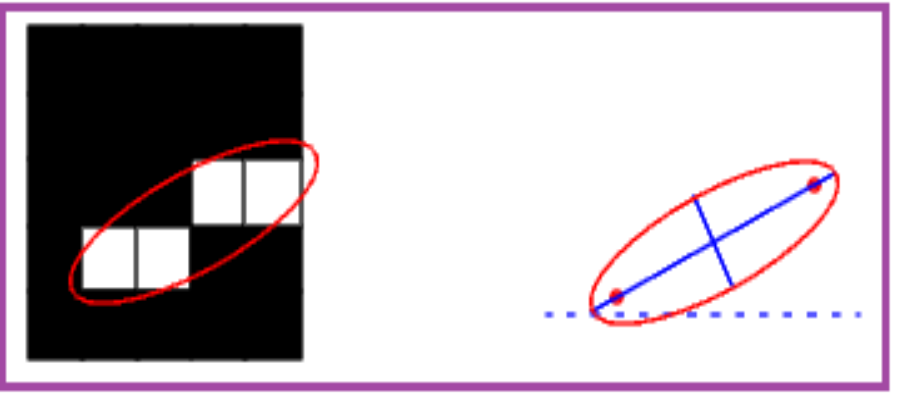

Figure 3: Object orientation

* Object Convex Hull: the smallest convex polygon that can contain the region. Each row of the matrix contains the $\mathrm{x}$ - and $\mathrm{y}$-coordinates of one vertex of the polygon.

* Object Major Axis Length: the length (in pixels) of the major axis of the ellipse that has the same normalized second central moments as the region.

* Object Minor Axis Length: the length (in pixels) of the minor axis of the ellipse that has the same normalized second central moments as the region.

\# Object Eccentricity: the eccentricity of the ellipse that has the same second-moments as the region. The eccentricity is the ratio of the distance between the foci of the ellipse and its major axis length. The value is between 0 and 1.

* Object Euclidian distances: the distance between any two any two points (points coordinates ) p and q, the distance can be calculated using equation 1 .

$$
d(\mathrm{p}, \mathrm{q})=\left(\left(p_{1}-q_{1}\right)^{2}+\left(p_{2}-q_{2}\right)^{2}+\left(p_{3}-q_{3}\right)^{2}\right)^{1 / 2}
$$

\section{III.PROPOSED METHODOLOGY}

The proposed methodology as shown in figure 4 can be easily implemented applying the following steps:

1. Get the image.

2. If the image color then convert the image to gray color.

3. Covert the gray image to binary image.

4. Remove all objects with size less than a selected one bwareaopen matlab function.

5. Retrieve the objects number in the image applying bwlabel matlab function.

6. Apply objects labeling using and get the necessary objects information using regionprops matlab function. 


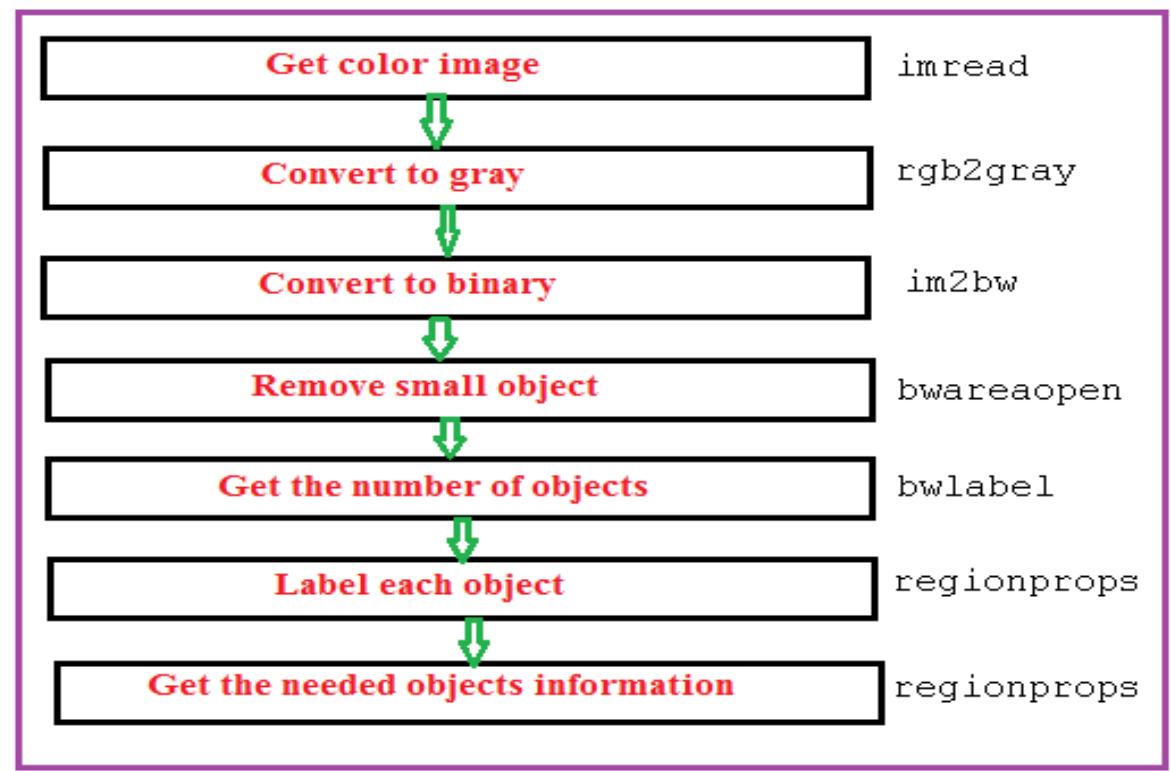

Figure 3: Proposed methodology

\section{IV.IMPLEMENTATION AND EXPERIMENTAL RESULTS}

The proposed methodology was implemented using matlab, several objects properties were measured, the obtained experimental results showed that each image has different properties, allowing us to form the image features and giving us the flexibility to select any number of these properties to create image features victor, figures 4 and 5 show the extracted objects of the used image 1 .

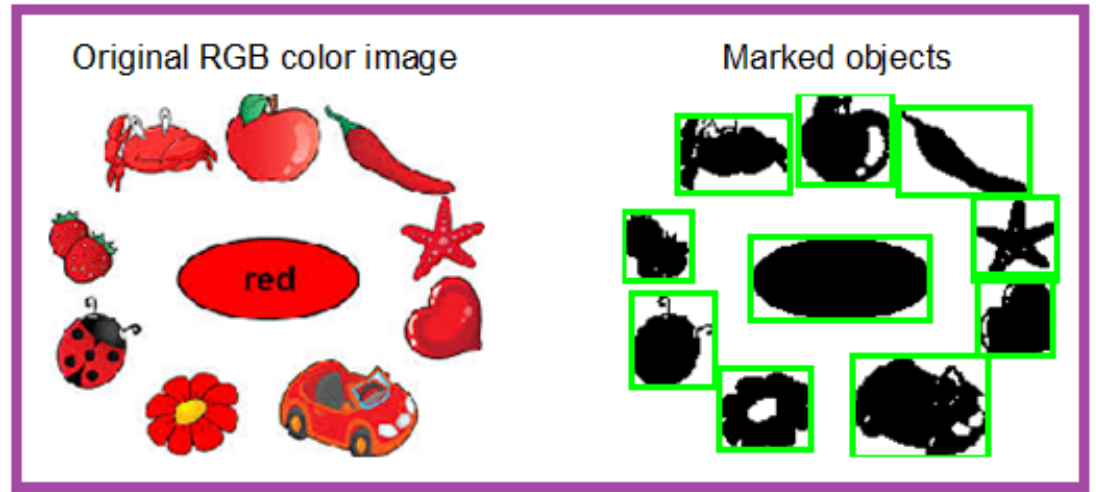

Figure 4: Objects in image 1

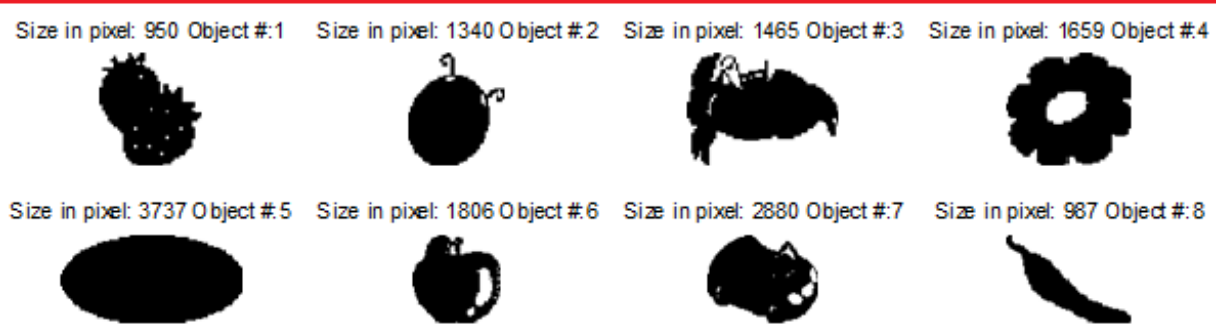

Size in pixel: 868 Object \#:9 Size in pixel: 1439 Object \#.10

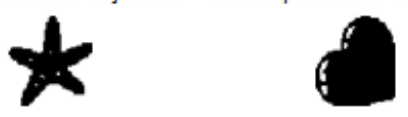

Figure 5: Objects sizes (Image 1) 


\section{DOI 10.17148/IJARCCE.2020.91208}

For image 1 we retrieve the objects centroids, here we can use the Euclidian distance of centroids as a value of the image features (see table 1).

The object extrema property can be used to form the image features, figure 6 shows the extremas for the first 4 objects of image 1 .

\begin{tabular}{|rrrrrrrr}
\hline \multicolumn{2}{c}{ Object 1 } & \multicolumn{2}{c}{ Object 2 } & \multicolumn{2}{c}{ Object 3 } & \multicolumn{2}{c}{ Object 4 } \\
X_coor & \multicolumn{1}{c}{ Y_coor } & \multicolumn{1}{c}{ X_coor } & Y_coor & X_coor & Y_coor & \multicolumn{1}{c}{ X_coor } & Y_coor \\
11.5000 & 66.5000 & 23.5000 & 113.5000 & 42.5000 & 12.5000 & 84.5000 & 156.5000 \\
17.5000 & 66.5000 & 25.5000 & 113.5000 & 45.5000 & 12.5000 & 90.5000 & 156.5000 \\
39.5000 & 87.5000 & 52.5000 & 130.5000 & 94.5000 & 34.5000 & 107.5000 & 167.5000 \\
39.5000 & 88.5000 & 52.5000 & 133.5000 & 94.5000 & 40.5000 & 107.5000 & 183.5000 \\
24.5000 & 106.5000 & 26.5000 & 165.5000 & 40.5000 & 56.5000 & 79.5000 & 201.5000 \\
14.5000 & 106.5000 & 18.5000 & 165.5000 & 39.5000 & 56.5000 & 69.5000 & 201.5000 \\
0.5000 & 84.5000 & 5.5000 & 153.5000 & 31.5000 & 37.5000 & 54.5000 & 179.5000 \\
0.5000 & 78.5000 & 5.5000 & 140.5000 & 31.5000 & 31.5000 & 54.5000 & 176.5000 \\
\hline
\end{tabular}

Figure 6: Extremas of the first 4 objects of image 1

Table 1: Some properties of image 1 objects

\begin{tabular}{|c|c|c|c|c|c|}
\hline \multirow{2}{*}{ Object number } & \multicolumn{3}{|c|}{ Centroid } & $\begin{array}{c}\text { Euclidian } \\
\text { distance of } \\
\text { Extrema }\end{array}$ & Area \\
\cline { 2 - 5 } & X_coordinates & Y_coordinates & 73.6614 & 950 & -50.1719 \\
\hline 1 & 87.7453 & 18.3916 & 125.8730 & 1340 & 60.2454 \\
\hline 2 & 143.6366 & 25.2746 & 44.5982 & 1465 & -0.3009 \\
\hline 3 & 32.9556 & 59.1686 & 97.6729 & 1659 & 18.3825 \\
\hline 4 & 179.2194 & 81.5467 & 62.1772 & 3737 & -0.0050 \\
\hline 5 & 104.4549 & 123.8416 & 164.7938 & 1806 & -25.5614 \\
\hline 6 & 26.9707 & 124.4358 & 14.7648 & 2880 & -12.3192 \\
\hline 7 & 176.8076 & 167.3549 & 212.1367 & 987 & -33.5448 \\
\hline 8 & 38.1621 & 189.7143 & 232.6478 & 868 & 33.8817 \\
\hline 9 & 83.1613 & 221.9747 & 176.1051 & 1439 & 57.2337 \\
\hline 10 & 127.8610 & 224.3419 & 137.1841 & & \\
\hline Euclidian distance of centroids & & & & \\
\hline
\end{tabular}

Other valuable information are Major Axis Length, Minor Axis Length, Eccentricity, and Euclidian distance of convex Hull, these information can also be used to form the image features (see table 2); figure 7 shows the extracted convex Hull coordinate for the first two objects of image 1: 
DOI 10.17148/IJARCCE.2020.91208

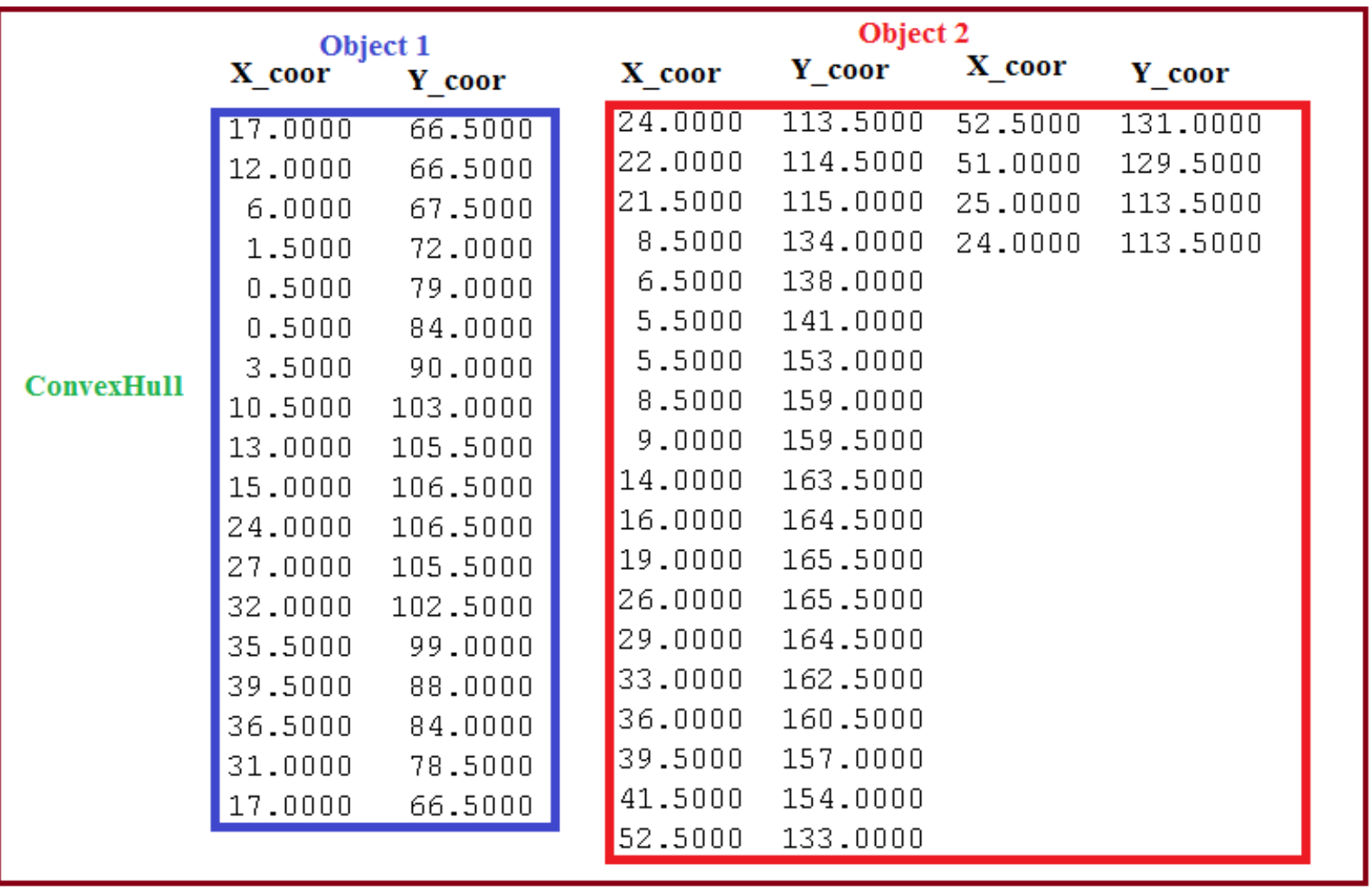

Figure 7: Convex Hull coordinates of the first 2 objects of image 1

Table 2: Properties averages as a features part

\begin{tabular}{|c|c|c|c|c|}
\hline Object number & Major Axis Length & Minor Axis Length & Eccentricity & $\begin{array}{c}\text { Euclidian distance } \\
\text { of convex Hull }\end{array}$ \\
\hline 1 & 43.5833 & 29.3228 & 0.7398 & 73.6240 \\
\hline 2 & 46.3202 & 38.9219 & 0.5422 & 128.7109 \\
\hline 3 & 66.9359 & 32.9937 & 0.8701 & 44.5702 \\
\hline 4 & 56.1328 & 45.3814 & 0.5885 & 128.0566 \\
\hline 5 & 102.4994 & 46.4369 & 0.8915 & 37.1012 \\
\hline 6 & 52.6359 & 48.9882 & 0.3658 & 173.3335 \\
\hline 7 & 77.3234 & 50.5356 & 0.7569 & 14.5774 \\
\hline 8 & 83.1386 & 18.8326 & 0.9740 & 219.2955 \\
\hline 9 & 43.1214 & 37.3140 & 0.5012 & 175.3981 \\
\hline 10 & 49.2243 & 39.1725 & 0.6056 & 165.4766 \\
\hline Average & 62.0915 & 38.7900 & 0.6836 & 111.1123 \\
\hline
\end{tabular}

Using some of the objects properties we can construct a features victor for each image, the victor value will be unique for each image and they can be used as a classifier to retrieve or recognize the image, table 3 shows an example of how to form a features victor for each image: 
DOI 10.17148/IJARCCE.2020.91208

Table 3: Example of images features victors

\begin{tabular}{|c|c|c|c|c|}
\hline \multirow{2}{*}{ Image number } & \multicolumn{4}{|c|}{ Features } \\
\cline { 2 - 5 } & Number of objects & $\begin{array}{c}\text { Euclidian distance of } \\
\text { centroids }\end{array}$ & Average area & Average eccentricity \\
\hline 1 & 10 & 137.1841 & 1713.1 & 0.6836 \\
\hline 2 & 16 & 62.9931 & 802.2500 & 0.7616 \\
\hline 3 & 9 & 144.9173 & 1834.7 & 0.8254 \\
\hline 4 & 6 & 128.9015 & 1315 & 0.7905 \\
\hline 5 & 3 & 56.5730 & 14343 & 0.4021 \\
\hline 6 & 139 & 332.3075 & 1165,5 & 0.7627 \\
\hline
\end{tabular}

\section{V.CONCLUSION}

A simple methodology was proposed to create image features victors to be used for image retrieval or image recognition. Based on the extracted object properties we can construct the image features victor, the objects properties provide us with a variety of information which can be used as an excellent source to form the image features. Getting th image objects information is very simple and useful, and it was shown that for each image (color or gray) we can easily for a unique values to be used as image classifier or identifier.

\section{REFERENCES}

[1] Majed O Al-Dwairi, Ziad A Alqadi, Amjad A Abujazar, Rushdi Abu Zneit, Optimized true-color image processing, World Applied Sciences Journal, vol. 8, issue 10, pp. 1175-1182, 2010.

[2] Jamil Al Azzeh, Hussein Alhatamleh, Ziad A Alqadi, Mohammad Khalil Abuzalata, Creating a Color Map to be used to Convert a Gray Image to Color Image, International Journal of Computer Applications, vol. 153, issue 2, pp. 31-34, 2016.

[3] Qazem Jaber Ziad Alqadi, Jamil azza, Statistical analysis of methods used to enhance color image histogram, XX International scientific and technical conference, 2017.

[4] Bassam Subaih Ziad Alqadi, Hamdan Mazen, A Methodology to Analyze Objects in Digital Image using Matlab, International Journal of Computer Science \& Mobile Computing, vol. 5, issue 11, pp. 21-28, 2016.

[5]Mazen A.Hamdan Bassam M.Subaih, Prof. Ziad A. Alqadi, Extracting Isolated Words from an Image of Text, International Journal of Computer Science \& Mobile Computing, vol. 5, issue 11, pp. 29-36, 2016.

[6] Dr. Amjad Hindi, Dr. Majed Omar Dwairi, Prof. Ziad Alqadi, Analysis of Procedures used to build an Optimal Fingerprint Recognition System, International Journal of Computer Science and Mobile Computing, vol. 9, issue 2, pp. 21 - 37, 2020.

[7]Ziad A AlQadi Amjad Y Hindi, O Dwairi Majed, PROCEDURES FOR SPEECH RECOGNITION USING LPC AND ANN, International Journal of Engineering Technology Research \& Management, vol. 4, issue 2, pp. 48-55, 2020.

[8] Aws AlQaisi, Mokhled AlTarawneh, Ziad A. Alqadi, Ahmad A. Sharadqah, Analysis of Color Image Features Extraction using Texture Methods, TELKOMNIKA, vol. 17, issue 3, pp. 1220-1225, 2019.

[9]Ahmad Sharadqh Naseem Asad, Ismail Shayeb, Qazem Jaber, Belal Ayyoub, Ziad Alqadi, Creating a Stable and Fixed Features Array for Digital Color Image, IJCSMC, vol. 8, issue 8, pp. 50-56, 2019.

[10] Ziad Alqadi, Dr. Mohammad S. Khrisat, Dr. Amjad Hindi, Dr. Majed Omar Dwairi, VALUABLE WAVELET PACKET INFORMATION TO ANALYZE COLOR IMAGES FEATURES, International Journal of Current Advanced Research, vol. 9, issue 2, pp. $2319,2020$.

[11] Majed O. Al-Dwairi, Amjad Y. Hendi, Mohamed S. Soliman, Ziad A.A. Alqadi, A new method for voice signal features creation, International Journal of Electrical and Computer Engineering (IJECE), vol. 9, issue 5, pp. 4092-4098, 2019.

[12]Ziad AlQadi, M Elsayyed Hussein, Window Averaging Method to Create a Feature Victor for RGB Color Image, International Journal of Computer Science and Mobile Computing, vol. 6, issue 2, pp. 60-66, 2017.

[13] Bilal Zahran Belal Ayyoub, Jihad Nader, Ziad Al-Qadi, Suggested Method to Create Color Image Features Victor, Journal of Engineering and Applied Sciences, vol. 14, issue 1, pp. 2203-2207, 2019.

[14]Majed O. Al-Dwairi, Amjad Y. Hendi, Mohamed S. Soliman, Ziad A.A. Alqadi, A new method for voice signal features creation, International Journal of Electrical and Computer Engineering (IJECE), vol. 9, issue 5, pp. 4092-4098, 2019.

[15]Ayman Al-Rawashdeh, Ziad Al-Qadi, Using wave equation to extract digital signal features, Engineering, Technology \& Applied Science Research, vol. 8, issue 4, pp. 1356-1359, 2018.

[16]Ahmad Sharadqh Naseem Asad, Ismail Shayeb, Qazem Jaber, Belal Ayyoub, Ziad Alqadi, Creating a Stable and Fixed Features Array for Digital Color Image, IJCSMC, vol. 8, issue 8, pp. 50-56, 2019.

[17]ZIAD ALQADI, A MODIFIED LBP METHOD TO EXTRACT FEATURES FROM COLOR IMAGES, Journal of Theoretical and Applied Information Technology, vol. 96, issue 10, pp. 3014-3024,2018.

[18]Aws Al-Qaisi, Saleh A Khawatreh, Ahmad A Sharadqah, Ziad A Alqadi, Wave File Features Extraction Using Reduced LBP, International Journal of Electrical and Computer Engineering, vol. 8, issue 5, pp. 2780-2787, 2018. 


\section{DOI 10.17148/IJARCCE.2020.91208}

[19]Jihad Nader Ismail Shayeb, Ziad Alqadi, Jihad Nader, Analysis of digital voice features extraction methods, International Journal of Educational Research and Development, vol. 1, issue 4, pp. 49-55, 2019.

[20]Ahmad Sharadqh Jamil Al-Azzeh , Rashad Rasras, Ziad Alqadi , Belal Ayyoub, Adaptation of matlab K-means clustering function to create Color Image Features, International Journal of Research in Advanced Engineering and Technology, vol. 5, issue 2, pp. 10-18, 2019.

[21] Yousf Eltous Ziad A. AlQadi, Ghazi M. Qaryouti, Mohammad Abuzalata, ANALYSIS OF DIGITAL SIGNAL FEATURES EXTRACTION BASED ON KMEANS CLUSTERING, International Journal of Engineering Technology Research \& Management, vol. 4, issue 1, pp. 66-75, 2020.

[22]Amjad Y Hindi, Majed O Dwairi, Ziad A AlQadi, Creating Human Speech Identifier using WPT, International Journal of Computer Science and Mobile Computing, vol. 9, issue 2, pp. 117-123, 2020.

[23]Amjad Hindi, Majed Omar Dwairi, Ziad Alqadi, Analysis of Digital Signals using Wavelet Packet Tree, IJCSMC, vol. 9, issue 2, pp. 96-103, 2020.

[24] Dr. Amjad Hindi, Dr. Ghazi M. Qaryouti, Prof. Yousif Eltous, Prof. Mohammad Abuzalata, Prof. Ziad Alqadi, Color Image Compression using Linear Prediction Coding, International Journal of Computer Science and Mobile Computing, vol. 9, issue 2, pp. 13 - $20,2020$.

[25] Ziad Alqad, Majid Oraiqat, Hisham Almujafet, Salah Al-Saleh, Hind Al Husban, Soubhi Al-Rimawi, A New Approach for Data Cryptography, International Journal of Computer Science and Mobile Computing, vol. 8, issue 9, pp. 30-48, 2019.

[26] Ziad Alqadi, Ahmad Sharadqh, Naseem Asad, Ismail Shayeb, Jamil Al-Azzeh, Belal Ayyoub, A highly secure method of secret message encoding, International Journal of Research in Advanced Engineering and Technology, vol. 5, issue 3, pp. 82-87, 2019 